\title{
UTICAJ ULJANOG EKSTRAKTA RAČIĆA SA DODATKOM POLIKOZANOLA I KOENZIMA Q10 NA METABOLIZAM LIPIDA KOD PACIJENATA SA POREMEĆAJEM FUNKCIJE ŠTITASTE ŽLEZDE
}

\section{Uvod}

Poremećaj metabolizma lipida kod oboljenja štitaste žlezde spada u grupu sekundarnih hiperlipoproteinemija. Računa se da je hipotireoidizam uzrok oko $2 \%$ svih slučajeva hiperlipidemija, što se tiče endokrinih bolesti i zauzima drugo mesto kao uzročnik sekundarnih hiperlipoproteinemija, odmah iza šećerne bolesti. Hipotireoza se karakteriše porastom nivoa holesterola u plazmi i to na račun LDL frakcije, što je posledica smanjene ekspresije LDL receptora u jetri, koji su osetljivi na delovanje trijodtironina. Nivo LDL holesterola može biti povišen čak i kod pacijenata sa supkliničkom formom hipotireoze. Kod pacijenata sa hiperfunkcijom štitaste žlezde zbog pojačanog lučenja hormona štitaste žlezde vreme prolaska hrane kroz gastrointestinalni trakt je skraćeno, pa su stolice učestale, često sa dijarejom, nekada i sa steatorejom, pa je nivo lipida u krvi snižen. (Harison 2004)

Lek kojim sam lečila poremećaj metabolizma lipida sadrži ulje račića (Krill Oil $500 \mathrm{mg}$ ), koji štiti kardiovaskularni sistem i održava normalne vrednosti holesterola, koenzim Q10 ( 51,5 mg) koji štiti ćelije od oksidativnog oštećenja i doprinosi stvaranju energije u celom organizmu, polikozanole ( $20 \mathrm{mg}$ ) koji deluju direktno na ćelije koje kontrolišu sintezu i razgradnju holesterola. Polikozanoli inhibiraju sintezu holesterola u jetri korak pre sinteze mevalonata, snižavajući ćelijsku ekspresiju HMG - COA reduktaze, utiču na katabolizam LDL-holesterola, povećavajući afinitet receptora za LDL, čime se povećava transport LDL čestica u hepatocite gde se razgrađuju. Lek sadrži i omega 3 i omega 6 masne kiseline, koje povećavaju nivo HDL holesterola, a snižavaju ukupan nivo triglicerida u krvi.

\section{Cilj rada}

Pokazati uticaj uljanog ekstrakta račića sa dodatkom polikozanola i koenzima Q10 na nivo holesterola i triglicerida u krvi kod pacijenta sa poremećajem funkcije štitaste žlezde. 


\section{Materijal i metode}

Svim pacijentima obuhvaćenim ovim radom izmeren je hormonski status štitaste žlezde (FT4 I TSH), kao i nivo ukupnog holesterola, triglicerida, AST I ALT-a. Nivo FT4 I TSH smo izmerili na aparatu DPC Immulite 1000, dok je nivo holesterola, triglicerida, AST I ALT izmeren na aparatu ILAB 300+.

Pacijenti obuhvaćeni ovim radom nisu imali pridružena oboljenja.

\section{Rezultati rada}

\begin{tabular}{|l|l|l|c|c|c|c|c|}
\hline & INICIJA. & BOLEST & $\begin{array}{c}\text { HOLESTEROL } \\
\text { PRE }\end{array}$ & $\begin{array}{c}\text { TRIGLICERIDI } \\
\text { PRE }\end{array}$ & $\begin{array}{c}\text { DUŽINA } \\
\text { TERAPIJE }\end{array}$ & $\begin{array}{c}\text { HOLESTEROL } \\
\text { POSLE }\end{array}$ & $\begin{array}{c}\text { TRIGLICERIDI } \\
\text { POSLE }\end{array}$ \\
\hline 1. & M.B. & Hypothyreosis & 6,99 & 2,40 & 20 dana & 5,41 & 1,83 \\
\hline 2. & M.M. & Hypothyreosis & 10,20 & 3,04 & 2 meseca & 8,50 & 1,88 \\
\hline 3. & H.A. & Hypothyreosis & 7,20 & 3,22 & 14 dana & 5,19 & 1,93 \\
\hline 4. & J.Lj. & Hypothyreosis & 7,77 & 3,53 & 1 godina & 6,18 & 2,22 \\
\hline 5. & Š.D. & Hypothyreosis & 6,96 & 2,22 & 1 godina & 5,48 & 2,18 \\
\hline 6. & S.D. & Hypothyreosis & 8,44 & 0,72 & 8 meseci & 6,28 & 0,76 \\
\hline 7. & P.D. & Hypothyreosis & 8,11 & 3,05 & 10 meseci & 6,19 & 2,22 \\
\hline 8. & M.V. & Hypothyreosis & 7,17 & 2,67 & 5 meseci & 5,48 & 1,98 \\
\hline 9. & J.B. & Hyperthyreosis & 7,67 & 1,91 & 5 meseci & 6,43 & 2,63 \\
\hline 10. & A.M. & Hypothyreosis & 7,46 & 1,13 & 11 meseci & 6,49 & 1,14 \\
\hline 11. & C..S. & Hypothyreosis & 8,19 & 3,74 & 5 meseci & 6,64 & 1,59 \\
\hline 12. & K.J. & Hypothyreosis & 7,50 & 2,51 & 4 meseca & 6,72 & 2,17 \\
\hline 13. & A.D. & Hypothyreosis & 6,40 & 3,52 & 4 meseca & 5,37 & 2,95 \\
\hline 14. & M.S. & Hypothyreosis & 7,59 & 1,07 & 7 meseci & 7,02 & 1,09 \\
\hline 15. & R.V. & Hyperthyreosis & 8,29 & 2,10 & 3 meseca & 4,37 & 1,63 \\
\hline 16. & S.Lj. & Hypothyreosis & 8,90 & 2,15 & 3 meseca & 7,91 & 0,78 \\
\hline 17. & P.R. & Hypothyreosis & 7,83 & 2,27 & 4 meseca & 4,98 & 1,92 \\
\hline 18. & A.B. & Hypothyreosis & 6,28 & 1,31 & 5 meseci & 4,47 & 1,08 \\
\hline 19 & M.R. & Hyperthyreosis & 7,10 & 2,13 & 6 meseci & 5,34 & 2,12 \\
\hline 20. & R.M. & Hypothyreosis & 7,40 & 0,97 & 6 meseci & 5,69 & 1,02 \\
\hline 21. & P.M. & Hypothyreosis & 8,18 & 1,49 & 3 meseca & 4,70 & 1,36 \\
\hline & & & & & & \\
\hline
\end{tabular}




\begin{tabular}{|l|c|l|c|c|c|c|c|}
\hline & INICIJA. & BOLEST & $\begin{array}{c}\text { HOLESTEROL } \\
\text { PRE }\end{array}$ & $\begin{array}{c}\text { TRIGLICERIDI } \\
\text { PRE }\end{array}$ & $\begin{array}{c}\text { DUŽINA } \\
\text { TERAPIJE }\end{array}$ & $\begin{array}{c}\text { HOLESTEROL } \\
\text { POSLE }\end{array}$ & $\begin{array}{c}\text { TRIGLICERIDI } \\
\text { POSLE }\end{array}$ \\
\hline 22. & V.M. & Hypothyreosis & 7,39 & 0,91 & 9 meseci & 6,44 & 0,70 \\
\hline 23. & V.N. & Hypothyreosis & 9,73 & 3,70 & 9 meseci & 6,56 & 1,38 \\
\hline 24. & N.O. & Hypothyreosis & 7,60 & 2,28 & 3 meseca & 6,54 & 1,98 \\
\hline 25. & M.G. & Hypothyreosis & 7,00 & 1,22 & 6 meseci & 6,32 & 1,42 \\
\hline 26. & A.M. & Hypothyreosis & 7,97 & 6,52 & 5 meseci & 6,15 & 3,55 \\
\hline 27. & R.D. & Hypothyreosis & 8,00 & 4,16 & 6 meseci & 6,02 & 3,82 \\
\hline 28. & S.R. & Hypothyreosis & 8,35 & 1,66 & 11 meseci & 7,70 & 1,10 \\
\hline 29. & T.J. & Hypothyreosis & 6,85 & 1,19 & 5 meseci & 5,96 & 1,11 \\
\hline 30. & D.B. & Hyperthyreosis & 8,56 & 1,85 & 4 meseca & 7,85 & 1,77 \\
\hline
\end{tabular}

\section{Diskusija}

U radu su od 30 pacijenata, 29 bile osobe ženskog pola.

Od ukupno 30 pacijenata 26 je imalo poremećaj funkcije štitaste žlezde u smislu smanjene funkcije - hypothyreosis, što je $87 \%$ uzorka .

Tri pacijenta (10\%), od ukupno 30 kod kojih je primenjivan lek, i na početku i na kraju terapije su imali lako smanjenu funkciju štitaste žlezde. Imali su normalnu vrednost slobodnog tiroksina i lako povišen nivo TSH-a. Svi ostali pacijenti kod kojih sam primenjivala lek bili su u eutireoidnom stanju, odnosno adekvatno supstituisani (lečeni), što znači da poremećaj metabolizma masti nisu imali od poremećene funkcije štitaste žlezde.

Šest pacijenata, što je 20\% uzorka, bilo je na stogoj redukcionoj dijeti (1200-1500 kcal) prilikom primene leka.

Najviši nivo holesterola koji sam lečila ovim lekom bio je $10,20 \mathrm{mmol} / 1$, kod pacijentkinje koja nije bila gojazna i sve vreme je bila adekvatno supstituisana levotiroksinom. Nivo holesterola se za 2 meseca primene leka, uz redukcionu dijetu, smanjio za $1,7 \mathrm{mmol} / 1$, što je smanjenje za $16,6 \%$ od početne vrednosti nivoa holesterola.

Kod iste pacijentkinje i nivo triglicerida je bio iznad gornje granice normale 3,04 , a korigovao se za 2 meseca na $1,88 \mathrm{mmol} / \mathrm{L}$, što je smanjenje za $38,2 \%$ od početne vrednosti.

Najviši nivo triglicerida kod koga sam prmenila ovaj lek bio je $6,52 \mathrm{mmol} / \mathrm{l}$, kod mlade gojazne devojke, sa poremećenim menstrualnim ciklusom. Ona je u trenutku dijagnoze povišenih nivoa triglicerida u krvi bila adekvatno supstituisana levotiroksinom. Sa korekcijom telesne težine i primenom leka, tokom pet meseci, korigovan je nivo triglicerida na $3,55 \mathrm{mmol} / \mathrm{L}$ i uredio se menstrualni ciklus. Sniženje nivo triglicerida je iznosilo $45,6 \%$ u odnosu na početnu vrednost nivoa triglicerida u krvi. 
Najbolji uspeh što se tiče sniženja nivoa holesterola pokazan je kod pacijentkinje koja je imala hiperfunkciju štitaste žlezde, ali je u trenutku dijagnostikovanja poremećaja metabolizma masti bila u eutireoidnom stanju. Kod nje je za 3 meseca, uz primenu leka i dijetalnu ishranu, nivo holesterola snižen sa 8,29 na $4,37 \mathrm{mmol} / 1$, a i nivo triglicerida je značajno redukovan sa 2,10 na $1,63 \mathrm{mmol} / \mathrm{L}$.

Praćena je i dužina trajanja terapije, koja se kretala od 14 dana do 12 meseci.

Prosečna dužina trajanja terapije bila je 5 meseci.

Najkraće je trajala terapija kod pacijentkinje na Programu za mršavljenje, koja je bila na dijetalnoj ishrani $1200 \mathrm{kcal} / \mathrm{dan}$ i primenjivala propisani lek, 14 dana. Za to vreme nivo holesterola je snižen sa 7,20 na $5,19 \mathrm{mmol} / 1$, tako da je nivo holesterola snižen za $28 \%$ od početne vrednosti.

Nivo triglicerida kod iste pacijentkinje snižen je sa 3,22 , na $1,93 \mathrm{mmol} / \mathrm{l}$, za isti period, tako da je sniženje $40 \%$ od početne vrednosti.

Terapiju sam kratko primenjivala i kod mlade mršave pacijentkinje sa smanjenom funkcijom štitaste žlezde, koja je bila eutireoidna u momentu dijagnostikovanja poremećenog metabolizma masti, ali je bila u pripremi za IVF. Tako da smo uz lek i strogu redukcionu dijetu uspeli da spustimo nivo holesterola sa 6,99 na $5,22 \mathrm{mmol} / 1$, a nivo triglicerida sa 2,40 na $1,83 \mathrm{mmol} / \mathrm{L}$. Sniženje nivoa holesterola i nivoa triglicerida u ovom slučaju bilo je potpuno isto, $25 \%$ od početne vrednosti.

Najduže lečenje je bilo 12 meseci kod pacijentkinje koja je bila gojazna i nije vodila računa o ishrani, ali je propisan lek koristila redovno. Sve vreme pacijentkinja je adekvatno supstituisana levotiroksinom. Nivo holesterola za 12 meseci terapije snižen je sa 6,96 na $5,48 \mathrm{mmol} / \mathrm{L}$, što je $21 \%$ od početne vrednosti nivoa holesterola. Nivo triglicerida je pokazao neznatno sniženje za ovaj period.

Drugi pacijent koji je lečen 12 meseci je jedini pacijent muškog pola iz uzorka, gojazan, nije držao dijetu, ali je propisani lek uzimao redovno. Kod njega redukcija nivoa holesterola sa 7,77 na $6,18 \mathrm{mmol} / 1$, što je $20 \%$ od početne vrednosti nivoa holesterola. Nivo triglicerida je bio 3,53 na početku terapije, dok je na kraju bio 2,2 $\mathrm{mmol} / \mathrm{L}$, što je sniženje $38 \%$ od početne vrednosti nivoa triglicerida u krvi.

Svim pacijentima izmeren je nivo transaminaza pre i posle upotrebe leka.

Vrednosti transaminaza kod svih 30 pacijenata, obuhvaćenih ovim radom, sve vreme su bile u granicama normale, kako pre, tako i nakon upotrebe leka, bez obzira na dužinu trajanja terapije.

Nijedan pacijent kod koga je primenjena terapija nije imao neželjene efekte leka.

U radu koji je meni bio dostupan iz 2004. godine, gde je primenjivan samo krill oil, ali u različitoj dozi od 1,0 do 3,0 g na dan, zavisno od BMI, došlo je do značajnog smanjenja nivoa glukoze, ukupnog holesterola, LDL-holesterola i triglicerida.

Drugi rad koji datira još iz 1995. godine, kod koga su u terapiji hiperholesterolemije upotrebljavani samo polikozanoli u različitim dozama, tako što se nedeljno doza leka povećavala za $5 \mathrm{mg}$. Doza leka se povećavala na 8 nedelja, a maksimalno je bilo 
20 mg dnevno, koliko ima i u leku koji sam ja primenjivala. Pokazalo se značajno smanjenje nivoa LDL-holesterola, ukupnog holesterola i povećanje nivoa HDL-holesterola. Uticaj na nivo triglicerida nije bio značajan. U tom radu je pokazano da su se polikozanoli dobro tolerisali, nije bilo neželjenih efekata prilikom njihove primene.

\section{Zaključak}

Primena leka koji sadrži kombinaciju krill oil, koenzima Q10 i polikozanole u terapiji hiperlipoproteinemija, kod pacijenata sa poremećajem funkcije štitaste žlezde, pokazala se veoma efikasnom, kao prva linija terapije.

Uspeh terapije ovim lekom zavisio je prvenstveno od režima ishrane.

Lek se pokazao efikasnim čak i prilikom kratkotrajne primene, ali uz strogu redukcionu dijetu.

\section{Literatura}

1. Harison (2004). Interna medicina.

2. Buena R, El Farrah K, Deutsh L. Evaluation of the effects of Neptune Krill Oil on the Clinical Course of Hyperlipidemia. Alter Med. Rev. 2004; 9 (4): 420-428.

3. Canneti M, Morera M, Illinait J, et all. ( 1995). A two year study on the efficacy and tolerabillity of policosanol in patient with tipe II hypercholesterolemia. Intern J.Clin. Pharmacol. Res 15; 159-165. 